\title{
Pengaruh latihan fisik akut terhadap fev (forced expiratory volume in one second) pada pemain basket mahasiswa Fakultas Kedokteran Unsrat
}

\author{
${ }^{1}$ Grace N. Dumat \\ ${ }^{2}$ Joice N. A. Engka \\ ${ }^{2}$ Ivony M. Sapulete
}

\begin{abstract}
${ }^{1}$ Kandidat Skripsi Fakultas Kedokteran Universitas Sam Ratulangi Manado
${ }^{2}$ Bagian Fisiologi Fakultas Kedokteran Universitas Sam Ratulangi Manado Email: geeyii.gnd@gmail.com
\end{abstract}

\begin{abstract}
Acute physical exercise is an exercise activity that is carried out with a long duration of \pm 10 - 15 minutes with mild to moderate intensity. Several studies have shown that reduced physical exercise may lower lung resistance. Physical exercise causes an increase in respiratory muscle endurance so that respiratory function will increase. One assessment measure lung function $F E V_{l}$ (Forced Expiratory Volume in One Second) by using a spirometry. The objective of this study is to overlook the effect of physical exercise on lung function of $F E V_{l}$ at medical student basketball players in Sam Ratulangi University. The subject of this study are 35 medical students that have been active playing basketball for more or less than 6 months within 10-15 minutes exercise duration. Subject was measured with spirometry to see the effect of this treatment on $F E V_{1}$. All of 35 subjects finish this program. FEV1 before the treatment was 3.4871 and 3.4474 after treatment. Conclusion: FEV1 increase about 0,73 litres, but it's not statistically significant $(p>0,05)$
\end{abstract}

\begin{abstract}
Abstrak: Latihan fisik akut adalah aktivitas olahraga yang dilakukan dengan durasi latihan \pm 10-15 menit dengan intensitas ringan-sedang. Penelitian menunjukan bahwa terjadi penurunan daya tahan paru yang diakibatkan oleh kurangnya aktivitas fisik olahraga. Latihan fisik meningkatkan daya tahan otot pernapasaan sehingga dapat melancarkan aliran darah ke dalam paru dan meningkatkan kapasitas paru. Salah satu penilaian yang dapat dilakukan untuk menilai faal paru yaitu dengan menilai $F E V_{l}$ (Forced Expiratory Volume in One Second) dengan menggunakan alat spirometri. Penelitian ini bertujuan untuk mengetahui pengaruh latihan fisik akut terhadap $F E V l_{1}$ faal paru pada pemain basket mahasiswa kedokteran Unsrat, subyek penelitian terdiri dari 35 orang mahasiswa kedokteran yang aktif bermain basket \pm 6 bulan dengan durasi latihan fisik selama 10-15menit. $F E V_{l}$ subyek diukur sebelum diberikan perlakuan. Kemudia subyek diberikan perlakuan latihan fisik berupa permainan bola basket dengan durasi latihan selama 10-1 menit. FEV1 diukur kembali setelah dilakukan perlakuan. Keseluruhan subyek total 35 orang mengikuti program. Nilai $F E V_{1}$ sebelum perlakuan adalah $3.4871 \mathrm{~L}$ dan nilai $F E V_{1}$ setelah perlakuan adalah 3.4474L. Simpulan: Terdapat peningkatan nilai rerata FEV1 sebesar 0,39 liter, namun setelah dilakukan uji $\mathrm{t}$ berpasangan menyatakan tidak ada perbedaan yang bermakna rerata FEV 1 awal dan akhir $(\mathrm{p}>0,05)$.
\end{abstract}

Latihan fisik merupakan kegiatan yang dilakukan untuk meningkatkan dan memelihara kebugaran tubuh, serta dianjurkan pada setiap indvidu agar terhindar dari berbagai penyakit. Pegaruh latihan fisik dapat berupa pengaruh positif yaitu menghambat atau merusak. Latihan fisk rutin dengan intesitas ringan sampai sedang dapat meningkatkan daya tahan dan kebugaran tubuh. Latihan fisik juga 
bermanfaat untuk meningkatkan kebugaran jantung paru, massa tulang, kekuatan otot, meningkatkan fungsi fungsi seksual dan masih banyak lagi. Berdasarkan data WHO, orang dengan latihan fisik tidak adekuat akan terjadi peningkatan pada semua penyebab kematian sebesar 20\% - 30\%, dibandingkan dengan orang yang latihan fisik minimal 150 menit intensitas sedang per minggu. Pada tahun 2010, $23 \%$ orang dewasa 18 tahun keatas, latihan fisiknya tidak adekuat. Prevalensi tertinggi ada pada daerah Amerika (32\%) dan terendah pada daerah Asia Tenggara (15\%). Sebuah studi mengatakan bahwa dengan meningkatkan latihan fisik sebanyak 10\%, dapat mencegah kemaian sebanyak 533.000 jiwa/tahun, jika ditingkatkan sebanyak $25 \%, 1.300 .000$ kematian dapat dicegah. $1,2,3,4$

Latihan fisik dapat dibedakan berdasarkan terlatih atau tidak terlatih, yakni latihan fisik akut atau pada orang yang tidak terlatih, tidak terprogram atau terstruktur dan latihan fissik kronik atau terlatih pada atlet yang terprogram,terstruktur dan memiliki daya saing. Berdasarkan penggunaan oksigennya latihan fisik dua yaitu latihan fisik aerobik dan anaerobik. Pada latihan fisik aerobic memerlukan oksigen untuk pembentukan energy, sedangkan latihan fisik anaerobik tidak memerlukan oksigen untuk pembentukan energy, sedangkan latihan fisik anaerobik tidak memerlukan oksigen untuk pembentukan energy. Contoh jenis latihan aerobik termasuk jogging,

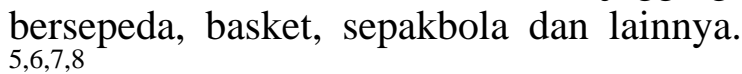

Pada olahraga bola basket pemain basket memiliki beberapa kemampuan fisiologis yang sangat penting agar dapat berprestasi, berlatih, dan bertanding dengan maksimal. Kemampuan fisiologis yang dibutuhkan atlet untuk berprestasi maksimal antara lain: daya tahan jantung paru (cardiovascular endurance), kapasitas vital pau-paru (Vital capacity, VC), volume ekspirasi paksa satu detik (Forced Expiratory Volume in One Second, $\left.\mathrm{FEV}_{1}\right)$, dan kemampuan otot yang maksimal. $^{9}$

Kemampuan pernapasan seseorang bersifat relatif lebih kecil bila dibandingkan dengan seseorang yang merupakan atlet, pernapasan merupakan hal yang penting untuk penampilan yang baik pada atlet yang membutuhkan daya tahan. Pemeriksaan faal paru merupakan parameter untuk mengkaji seberapa jauh perubahan atau kelainan anatomi akibat suatu penyakit yang memberikan perubahan atau gangguan faal paru. Di dalam dunia medis bisa digunakan untuk diagnostik, pemeriksaan faal paru juga dapat dipergunakan untuk mengevaluasi hasil suatu tindakan pengobatan. Pemeriksaan faal paru dapat mendeteksi kelainan paru secara dini sebelum keluhan lainnya muncul. ${ }^{10,11}$

Pengaruh gaya hidup secara global yang mengakibatkan banyak orang kurang dapat melakukan olahraga atau latihan fisik dalam aktifitas sehari-hari terutama pada kalangan mahasiswa. Kesenangan seperti menghabiskan waktu dengan bermain games, menonton tv, jalan-jalan, pengunaan komputer dan gadget serta dengan posisi duduk yang lama dapat mengakibatkan terjadinya hypokinetic atau yang disebut sebagai akibat gejala kurang bergerak sehingga akan berpengaruh pada produktifitas dan kesehatan tubuh. Hal ini yang mendasari peneliti untuk melihat apakah ada pengaruh latihan fisik akut pada pemain basket terhadap nilai $F E V_{l}$ pada mahasiswa kedokteran UNSRAT.

\section{METODE PENELITIAN}

Penelitian ini bersifat eksperimental lapangan dengan menggunakan rancangan pre-post one group design. Penelitian ini dilaksanakan di Fakultas Kedokteran Unsrat, Malalayang. Penelitian dilaksanakan pada bulan OktoberDesember 2015. Populasi dalam penelitian ini adalah mahasiswa pemain basket di Kedokteran Unsrat sebesar 35 pasien. Defenisi Operasional Latihan Fisik Akut adalah latihan fisik yang dilakukan pada orang yang tidak teerlatih atau bukn olahragawan, dengan suatu bentuk aktifitas 
fisik yang tidak terprogram dan tidak untuk bersaing dalam olahraga. $\mathrm{FEV}_{1}$ merupakan besarnya volume udara yang dikeluarkan dalam satu detik pertama. Lama ekspirasi pertama pada orang normal dapat berkisar 4-5 detik dan pada detik pertama orang normal dapat mengeluarkan udara pernapasan sebesar $80 \%$ dari nilai vital capacity (VC)

\section{HASIL PENELITIAN}

Berdasarkan Tabel 1 pada penelitian mengenai $F E V_{l}$ yang telah dilakukan terhadap pemain basket di fakultas kedokteran sebanyak 35 orang. Responden penelitian adalah mahasiswa yang aktif dalam olahraga basket lebih dari \pm 6 bulan distribusi umur subyek terbanyak pada usia 19 tahun sampai 21 tahun dengan nilai ratarata $(28,6 \%), 18$ sampai 20 tahun $(14,3 \%)$, 23 tahun $(8,6 \%)$ dan paling sedikit terdapat pada umur 22 tahun dan 17 tahun $(2,9 \%)$.

Tabel 1. Karakteristik subyek penelitian berdasarkan umur

\begin{tabular}{ccc}
\hline Umur & $\mathbf{N}$ & $\mathbf{( \% )}$ \\
\hline 17 & 1 & 2 \\
18 & 5 & 14 \\
19 & 10 & 28 \\
20 & 5 & 14 \\
21 & 10 & 28 \\
22 & 1 & 2 \\
23 & 3 & 8 \\
Total & 35 & 2 \\
\hline
\end{tabular}

Berdasarkan Tabel 2 Karakteristik Subyek Penelitian berdasarkan jenis kelamin terlihat bahwa distribusi terbanyak pasien terdapat 26 orang subyek laki-laki $(74,3 \%)$ dan 9 orang subyek perempuan $(25,7 \%)$. Berdasarkan tabel 3 menunjukan nilai $\mathrm{FEV}_{1}$ Pre-Post menurut batas umur $=<21$ dan $>=21$ tahun pada laki-laki dan perempuan yaitu 0,442 dan 0,403 pada laki-laki dan 0,790 dan 0,367 pada perempuan. Berdasarkan tabel 4 nilai deskriptif statistik $\mathrm{FEV}_{1}$ sebelum dan sesudah diberikan perlakuan latihan fisik olahraga basket Dari uji statistic nilai ukur $\mathrm{FEV}_{1}$ sebelum dan sesudah diberikan perlakuan latihan fisik didapatkan $\mathrm{FEV}_{1}$ Pre $-\mathrm{FEV}_{1}$ Post $250,00 \pm 228,00$ dan rerata $344,7429 \pm 358,7143$.

Tabel 2. Karakteristik subyek penelitian berdasarkan jenis kelamin

\begin{tabular}{lll}
\hline Jenis Kelamin & N & $(\mathbf{\% )}$ \\
\hline Laki-laki & 26 & 74.3 \\
Perempuan & 9 & 25.7 \\
Total & 35 & 100.0 \\
\hline
\end{tabular}

Tabel 3. Distribusi nilai deskriptif statistik Faal paru terhadap $F E V_{I}$ sebelum dan $F E V_{l}$ sesudah menurut usia $=<21$ dan $>=21$ berdasarkan jenis kelamin

\begin{tabular}{lcc}
\hline & $=<21$ (thn) & $>=21$ (thn) \\
& FEV $_{\text {pre }}-$ & FEV $_{\text {1 }}$ pre \\
& FEV $_{\mathbf{1}}$ post & FEV $_{\mathbf{1}}$ post \\
\hline Laki-laki & 0,442 & 0,403 \\
Perempuan & 0,790 & 0,367 \\
\hline
\end{tabular}

Tabel 4. Distribusi nilai deskriptif statistik $\mathrm{FEV}_{1}$ sebelum dan sesudah diberikan perlakuan latihan fisik olahraga basket

\begin{tabular}{cccc}
\hline N & FEVpre & FEVpost & Rerata \\
\hline 35 & 250,00 & 443,00 & 348,7143 \\
35 & 228,00 & 434,00 & 344,7429 \\
\hline
\end{tabular}

\section{BAHASAN}

Hasil penelitian ini data menunjukan dominan usia responden berada pada usia 19 dan 21 tahun dimana diketahui bahwa umur memiliki hubungan yang erat dengan daya tahan kardiorespirasi, dimana daya tahan kardiorespirasi terjadi secara fisiologis dari umur anak-anak hingga pada umur 20-30 tahun dan akan mencapai puncaknya pada umur 19-21 tahun dan mengalami penurunan seiring terjadinya penurunan daya tahan jantung, aliran darah dan paru yang juga akan mempengaruhi dan menurunkan daya kapasitas dari fungsional paru yang termasuk hasil penilaian didalamnya adalah $F E V_{l}{ }^{12}$

Dari hasil penelitian yang telah dilakukan didapatkan hasil pada karakteristik rata-rata usia 19 dan 21 ditemukan peningkatan. ${ }^{12}$

Salah satu kegunaan pemeriksaan faal 
paru termasuk didalamnya adalah $\mathrm{FEV}_{1}$ dimana hasil nilai dari pemeriksaan juga dipengaruhi oleh beberapa faktor diantaranya jenis kelamin, tinggi badan, berat badan serta indeks massa tubuh (IMT). ${ }^{13}$ Dari hasil penelitian yang dilakukan pada pemain basket mahasiswa kedokteran Unsrat ditemukan nilai normal $\mathrm{FEV}_{1}$ adalah 3,2 L/menit, dimana $\mathrm{FEV}_{1}$ Pre pada Laki-laki usia dibawah 21 tahun diperoleh hasil 0,442 dan perempuan 0,790, sedangkan pada $\mathrm{FEV}_{1}$ Post Laki-laki diatas usia 21 tahun ditemukan 0,403 dan $\mathrm{FEV}_{1}$ post pada perempuan 0,367 . Hal ini bisa terjadi dikarenakan faktor-faktor fisiologis yang antara lain yaitu jenis kelamin, tinggi badan, berat badan. Hal ini sama dengan penelitian yang dilakukan oleh Megawati D, yang menyatakan bahwa ada terjadi penurunan kapasitas vital paru yang berhungan erat dengan peningkatan berat badan. Sama halnya dengan penelitian yang dilakukan oleh Madina D, yang menyatakan hasil uji kolerasi terhadap setiap cabang olahraga yang diketahui terdapat hubungan yang cukup kuat antar nilai kapasitas vital paru dengan tinggi badan dan berat badan khususnya pada atlet pria dan wanita. ${ }^{13}$

Pemeriksaan FEV1 pada penelitian ini juga dilaksanakan sebelum diberikan perlakuan dalam hal ini pemberian latihan fisik dan kemudia sesudah latihan fisik. Hasil pemeriksaan ditemukan penurunan dari rerata FEV1 sebelum dan sesudah diberikan perlakuan yaitu $\mathrm{FEV}_{1}$ Pre $-\mathrm{FEV}_{1}$ Post 250,00 $\pm 228,00$ dan rerata 344,7429 $\pm 358,7143$. Hal ini diakibatkan karena latihan fisik mempunyai pengaruh terhadap fungsi paru. Latihan fisik secara rutin dapat meningkatkan aliran darah melalui paru yang menyebabkan kapiler paru mendapatkan supply oksigen dalam jumlah yang besar. ${ }^{14}$ Hasil ini tidak jauh berbeda dengan penelitian yang dilakukan oleh Farid dkk. (2005) dimana hasil dari penelitian yang dilakukan terhadap 18 subyek penderita penyakit asma yang dimasukan kedalam kelompok kasus, diberikan perlakuan berupa latihan fisik menggunakan alat olahraga treadmill yang dilaksanakan selama delapan minggu dengan frekwensi tiga kali dalam seminggu dan lama latihan inti diberikan selama 20 menit dengan menjaga denyut jantung maksimal pada 70\%-80\%. Pada penelitian ini ditemukan hasil yang menunjukan adanya kenaikan dari rerata FEV1 sebesar $0,39 \%{ }^{15}$

Latihan fisik yang dilakukan secara rutin dapat menyebabkan fungsi kerja paru meningkat karena terjadi peningkatan penggunaan oksigen dalam darah. Latihan fisik yang rutin dan teratur dapat meningkatkan kekuatan otot terutama otot pernapasaan yang menghasilkan intensitas yang cukup pada saat inspirasi sehingga terjadi peningkatan pada fungsi otot pernapasan. Faal paru memiliki hubungan yang besar terhadap aktivitas latihan fisik. Pada penderita gangguan faal paru seperti, asma atau penyakit paru obstruktif kronik, dan kelainan paru lainnya akan sangat berpengaruh terhadap latihan fisik, namun apabila latihan fisik dilakukan secara rutin dan teratur maka dapat meningkatkan kualitas dari faal paru terutama olahraga yang memiliki peran yang cukup besar dalam meningkatkan kapasitas paru. ${ }^{12,16,18}$

Hasil uji analisis dengan mengunakan SPSS terhadap FEV ${ }_{1}$ Faal Paru dengan uji t berpasangan menunjukan tidak terdapat perbedaan yang signifikan dimana nilai $p>$ 0,05 , dapat dikatakan hal ini terjadi akibat adanya penurunan $F E V_{l}$ terhadap beberapa sampel walaupun dalam ukuran yang kecil sewaktu dilakukan perlakuan latihan fisik, hal ini diakibatkan karena belum didapatkan adaptasi fisiologis yang baik terhadap sampel. ${ }^{15}$ Begitu juga halnya dengan penelitian yang dilakukan oleh Hanel dan Secher (1991) juga mendukung hal ini. Penelitian ini dilakukan dengan memberikan perlakuan yaitu latihan otot inspirasi pada 20 orang pelajar. Subyek dilatih menggunakan alat yang mempunyai kesamaan dengan powerlung, namun khusus digunakan untuk melatih otot inspirasinya dan dilakukan dalam dua kali sehari dan Penelitian yang dilakukan Thompson (2002) di menunjukan hasil yang sama. Penelitiannya dilakukan pada 
14 dari 111 sampel yang diberikan perlakuan latihan fisik dalam jangka waktu delapan minggu tidak mengalami peningkatan, sebaliknya nilai $\mathrm{FEV}_{1}$ subyek megalami penurunan, namun dilakukan lagi perlakuan untuk sampel yang sama selama delapan minggu setelahnya, hasil didapatkan bahwa terjadi peningkatan nilai $\mathrm{FEV}_{1}{ }^{12,19}$

\section{SIMPULAN}

Berdasarkan Hasil Penelitian dapat disimpulkan bahwa H0 diterima H1 ditolak. Tidak ada pengaruh latihan fisik akut terhadap $\mathrm{FEV}_{1}$ pada pemain basket mahasiswa kedokteran Unsrat.

\section{SARAN}

Perlu dilakukan penelitian yang lebih lanjut dengan populasi subyek syang lebih besar sehingga dapat memberikan hasil yang maksimal. Perlu dilakukan latihan fisik dalam jangka waktu lebih dari 8 minggu dengan lama latihan 20 menit maksimal 3x dalam seminggu

\section{DAFTAR PUSTAKA}

1. Matiandas WR. Pengaruh latihan fisik akut terhadap kadar gula darah mahasiswa Fakultas Kedokteran Universitas Sam Ratulangi Manado. Jurnal Biomedik. 2013;5.

2. World Health Organization. Prevelance of Insufficient physical activity. 2015. [Visited 2015 Oct 7]. Available from:

http;//www/who.int/gho/ncd/risk_fact ors/physical_activity_text/en/

3. Nat Geo Indonesia. 8 manfaat latihan fisik bagi kesehatan. 2014 March 2. [Visited 2015 sep 21]. Available from:

http://nationalgeography.co.id/berita/ 2014/03/8-manfaat-latihan-fisik-bagikesehatan

4. Park Alice. Lack of Exercise as Deadly as Smoking. 2012 July 18. [Visited 2015 Oct 03]. Available from: http://healthland.time.com/2012/07/1 8/lack-of-exercise-as-deadly-assmoking-study-finds/

5. Robergs RA, Robert So. Exercise physiology. Performance and clinical.
Mosby. 1997;389-405.

6. MedicineNet. Aerobic Exercise. 2015 January 26. [Visited 2015 Oct 2]. Available from: http://medicinenet.com/aerobic_exerc ise/page 3.html

7. Depertement of Health, The Government of the Hong Kong Special Administrative Region. Classification of physical activity and level of intensity. 2011. [Visited 2015 Sept 27]. Available from: http://www.change4health.gov.hk/en/ physical_activity/facts/classification/i ndex.html

8. USU Institutional Respiratory. ChapterII.pdf.2013 [visited 2015 Dec 29]. Available from: http://repository.usu.ac.id/bitstream/1 23456789/31340/4/Chapter\%20II.pdf

9. Patriana R, Berawi K, Sholeha TU. Perbedaan Kapasitas Vital Paru Dan Volume Ekspirasi Paksa Saru Detik Antara Siswa Anggota Tim Basktet Dan Siswa Yang Bukan Anggota Tim Basket. 2014. [visted Oktober $04^{\text {th }}$ 2015]. Available from: http://juke.kedokteran.unila.ac.id/inde x.php/majority/article/viewFile/181/1 79

10.Guyton AC, Hall E.J. 2007. Buku Ajar Fisiologi Kedokteran. Jakarta: ECG

11.Irfandi D, M.Yusuf Wibisono. Pengaruh Paparan Gas Toksik Lumpur Panas Pada Faal Paru. Majalah Kedokteran Respirasi. Jurnal Unair. 2010;1

12.Rasyid A. Kapasitas paru-paru sebelum dan sesudah berolahraga. [visited: January $8^{\text {th }}$ 2015]. Available from: http://id.scribd.com/doc/27970036/Ka pasitas-Paru-Paru-Sebelum-danSesudah-Berolahraga

13.Madina D. Nilai kapasitas vital paru dan hubungannya dengan karakterisktik fisik pada atlet berbagai cabang olahraga. [Tesis]. [Universitas Padjajaran. Bandung.2007

14. Yuleahka S. paparan Debu terhirup dan Gangguan Fungsi Paru pada Pekerja Industri Batu Kapur (Studi di Desa Mrisi Kecamatan Tanggungharjo Kabupaten Grobongan) [Thesis]. Semarang: Universitass Dipenogoro; 2007

15.Richart Raton. Pengaruh Latihan Aerobik 
Dumat, Engka, Sapulete: Pengaruh latihan fisik...

Terhadap Forced Expiratory Volume in One Second $\left(\mathrm{FEV}_{1}\right)$ Pada Mahasiswa Pria Dengan Kelebihan Berat Badan (Overweight). Fakultas Kedokteran Universitas Sam Ratulangi Manado. 2013:1:2

16.Hidayati I. Pengaruh latihan pembinaan jasmani militer terhadap nilai kapasitas vital paru dan volume ekspirasi paksa satu detik pertama siswa secaba di resimen induk daerah militer jaya (RINDAM JAYA) periode November 2011-Februari $2012 \quad$ [skripsi]. Universitas Pembangunan Nasional
"Veternan".Jakarta.2012

17.Warburton D, Nicol C, Bredin S. Health benefits of physical activity: the evidence. CMAJ. 2006;174(6):801-9

18.Sari F. Perbandingan pengaruh minuman beroksigen dengan meniman air biasa terhadap nilai VEP1, KVP, dan frekuensi napas pada latihan fisik [Skripsi]. Universitas Sumatera Utara. Medan.2011

19. Thompson B. Forced Expiration Exercise in Asthma and Their Effect on FEV. New Zealand Journal of Physiotherapy. 2012. h. 48-50. 